\title{
Improving productivity and water use efficiency: a case study of farms in England
}

Article

Accepted Version

Gadanakis, Y., Bennett, R., Park, J. and Areal, F. J. (2015) Improving productivity and water use efficiency: a case study of farms in England. Agricultural Water Management, 160. pp. 22-32. ISSN 0378-3774 doi:

https://doi.org/10.1016/j.agwat.2015.06.020 Available at https://centaur.reading.ac.uk/40537/

It is advisable to refer to the publisher's version if you intend to cite from the work. See Guidance on citing.

To link to this article DOI: http://dx.doi.org/10.1016/j.agwat.2015.06.020

Publisher: Elsevier

All outputs in CentAUR are protected by Intellectual Property Rights law, including copyright law. Copyright and IPR is retained by the creators or other copyright holders. Terms and conditions for use of this material are defined in the End User Agreement.

www.reading.ac.uk/centaur 
Central Archive at the University of Reading

Reading's research outputs online 


\section{Improving productivity and water use efficiency: a case study of farms in East Anglia} Yiorgos Gadanakis*a, Richard Bennett ${ }^{\mathrm{a}}$, Julian Park ${ }^{\mathrm{a}}$, Francisco Jose Areal ${ }^{\mathrm{a}}$

a School of Agriculture, Policy and Development, University of Reading, Whiteknights, PO Box 237, Reading, RG6 6AR, UK

* Corresponding Author. Tel. +44 7799041241 - e-mail addresses. g.gadanakis@reading.ac.uk, grgadanakis@gmail.com (Y. Gadanakis)

\section{Abstract}

The idea of Sustainable Intensification comes as a response to the challenge of avoiding resources such as land, water and energy being overexploited while increasing food production for an increasing demand from a growing global population. Sustainable Intensification means that farmers need to simultaneously increase yields and sustainably use limited natural resources, such as water. Within the agricultural sector water has a number of uses including irrigation, spraying, drinking for livestock and washing (vegetables, livestock buildings). In order to achieve Sustainable Intensification measures are needed that enable policy makers and managers to inform them about the relative performance of farms as well as of possible ways to improve such performance. We provide a benchmarking tool to assess water use (relative) efficiency at a farm level, suggest pathways to improve farm level productivity by identifying best practices for reducing excessive use of water for irrigation. Data Envelopment Analysis techniques including analysis of returns to scale were used to evaluate any excess in agricultural water use of 66 Horticulture Farms based on different River Basin Catchments across England. We found that farms in the sample can reduce on average water requirements by $35 \%$ to achieve the same output (Gross Margin) when compared to their peers on the frontier. In addition, $47 \%$ of the farms operate under increasing returns to scale, indicating that farms will need to develop economies of scale to achieve input cost savings. Regarding the adoption of specific water use efficiency management practices, we found that the use of a decision support tool, recycling water and the installation of trickle/drip/spray lines irrigation system has a positive impact on water use efficiency at a farm level whereas the use of other irrigation systems such as the overhead irrigation system was found to have a negative effect on water use efficiency.

Keywords: Data Envelopment Analysis, Water Use Efficiency, Technical Efficiency, Scale Efficiency, Benchmarking, East Anglia 


\section{1. Introduction}

31 Water is essential to agriculture production with uses comprising irrigation, spraying, drinking for 32 livestock and washing (vegetables, livestock buildings). In the UK water for agriculture is obtained either 33 directly from rivers and boreholes, or from the supply of mains waters as well as a combination of both 34 (Defra, 2011). The effect of extreme weather phenomena associated with climate change on water 35 availability has been studied (Chen et al., 2013; Daccache et al., 2011; Defra, 2009; Environment 36 Agency, 2008; Jenkins et al., 2009). Most of these studies conclude that the availability of water for 37 agriculture is under threat. The impacts for England in particular will be spatially and temporally variable 38 (Defra, 2009). Therefore, future projections for reduced rainfall during spring and summer time and the increase in the average temperature will lead to more frequent and extensive drought ${ }^{1}$ periods (Charlton

40 et al., 2010). The recent dry periods of 2011 and 2012 caused increased pressures in UK water 41 resources. In various catchments across the country, there was little or no water available for abstraction (FAS, 2013). Focusing on water use for irrigated root and vegetable crops, the continued production in 43 the south and east of England will be dependent on the provision of adequate sources of water for 44 irrigation. In addition, harvesting in wetter autumns could also be problematic (Charlton et al., 2010).

45 The main region within England for which water is crucial for agriculture production is the Anglian region 46 where the main use of water is for irrigation, both for the production of cash crops as well as for 47 horticulture. The average abstraction of water (excluding tidal) in the Anglian region for spray irrigation 48 between 2000 and 2012 was 50.5 million $\mathrm{m}^{3}$ accounting for the $59 \%$ of the average total water used in 49 agriculture for England. In terms of number of abstraction licences in force for spray irrigation in 2012,

\footnotetext{
1 "Drought is a nature produced but temporary imbalance of water availability, consisting of a persistent lower than average precipitation, of uncertain frequency, duration and severity, the occurrence of which is difficult to predict, resulting in diminished water resources availability and carrying capacity of the eco-systems". (Pereira et al., 2002)
} 
50 the Anglian region accounts for the $38 \%$ of total licences in England ${ }^{2}$. Irrigation in the East Anglian River

51 Basin Catchment (EARBC) and in the South East of England is mainly concentrated on cash-crop 52 production (potatoes and sugar beet) as well as horticulture and therefore it is considered as a major 53 production input to secure yield and income for the farmers, especially during dry periods. Irrigated 54 production delivers substantial economic benefits not only at the farm gate but also beyond that point since it supports a number of related businesses that provide equipment and farm supplies and are also responsible for the promotion and distribution of production. It can therefore be considered as an important factor for the development of the rural economy in East Anglia (Knox et al., 2009) and other regions of England with horticulture production like the South East, Thames, Humber, South West, etc. river basin catchment areas. The EARBC and England in general may face high pressures in future due to both a) an increase in water abstraction rates for agriculture due to increased water demand and increased number of abstraction licences and b) a decrease in water availability associated with changing weather conditions. The main climate threats are temperature increase and reduced precipitation (Defra, 2009; Environment Agency, 2008, 2011) with direct impacts on the hydrology structure of the area.

The Environment Agency (EA) is the water regulatory authority for England and is also responsible for the authorisation of abstraction licences (Environment Agency, 2013). Its primary responsibility is to balance the water needs of all abstractors (all industries involved in water abstraction including agriculture) with that of the natural environment. The EA considers water use efficiency as a need to save and manage water efficiently whilst at the same time promoting environmental sustainability.

Irrigated agriculture in England has therefore to achieve two goals in order to secure the future growth and the economic sustainability of the sector. The first objective is to maintain and improve productivity in order to meet increasing future food demand (FAO, 2011) but at the same time to preserve the associated natural environment. Intensive agricultural practices combined with the probability of more

\footnotetext{
2 Data comes from the "Water quality and abstraction statistics" published in the DEFRA website. The source of data is the Environment Agency. Available online at: https://www.gov.uk/government/statistical-data-sets/env15water-abstraction-tables : Accessed on 26.12.2013
} 
74 frequent dry periods in the area may increase the competition for water resources in an already over-

75 abstracted and over-licensed catchment (Knox et al., 2009). The Sustainable Intensification (SI) of

76 agricultural production is promoted as a mechanism that can balance the two objectives and at the

77 same time mitigate any conflicts between these two objectives. More specifically, the SI of agriculture

78 requires farmers to simultaneously increase their yields in order to meet the future demand for food,

79 but also to reduce environmental pressures generated by the production process (Garnett and Godfray,

80 2012).

81 In this sense, agricultural productivity and water use efficiency should be considered together when

82 evaluating the sustainability of farming systems. However, the social aim of sustainable farming systems

83 (i.e. increase productivity, being water use efficient) does not necessarily match with farmers business

84 aims (i.e. increase profitability). In order to close this gap between social and business objectives,

85 farmers, need to demonstrate efficient water use for renewing an irrigation abstraction licence (Knox et

86 al., 2012). For instance, a farmer may seek to maximise production and profit per unit of water (financial

87 sustainability) while the goal of an environmentally sustainable system could be to minimise the use of

88 water per value or volume of production (Knox et al., 2012). These contrasting approaches to efficiency

89 and also between increasing agricultural productivity and environmental preservation require a

90 management approach that simultaneously takes into consideration sustainability, productivity, and

91 profitability (Vico and Porporato, 2011).

92 For most farmers in England involved in high value crop production water use for irrigation is driven by

93 the need to produce a high quality product and hence obtain contracts and high prices from their

94 customers, particularly supermarkets (Knox et al., 2012). Therefore, economic incentives can play a

95 critical role in irrigation decisions (Oster and Wichelns, 2003). Knox et al. (2012) suggests that an

96 economically rational farmer, when there are unlimited water resources, would aim to use water until

97 the marginal benefit no longer exceeded the marginal cost. If the farmer fears that the water resources

98 may be inadequate, irrigation is restricted to the most (financially) responsive crops. Water use

99 efficiency is therefore considered as an economically driven parameter strongly related to the production

100 and marginal profit of a farm. The Farm Business Survey in England 2009/2010 also recorded financial 
101 or customer reasons as the primary reasons (55\%) for farmers carrying out management practices for

102 efficient water use in irrigation (Defra, 2011).

103 In addition, Knox et al. (2012) suggest that excess irrigation is avoided when the farmer is aware of the 104 risk of increased crop disease, has difficult land access and/or has concerns about the risk of fertiliser 105 leaching. Most farmers therefore sensibly aim for best (or reasonable) use of a potentially limited water 106 supply, aiming not to over or under irrigate (especially in the case of dry summers), whilst minimising 107 any non-beneficial losses (e.g. run-off, leaching). This is often described as "applying the right amount 108 of water at the right time in the right place".

109 Water demanded for irrigation at a farm level depends on farmers' decisions on when and which crop 110 to produce, the volume and the frequency of irrigation and also the selection of irrigation method and 111 technology (Marques et al., 2005). It is therefore a decision related to the production technology and 112 the management ability of the farmer. Vico and Porporato (2011), note that there are a number of 113 uncertainties in relation to both the economic and productivity goals of a farmer that increase the 114 complexity of the choice of a sustainable and efficient water management strategy. These uncertainties 115 are related to pests and diseases, temperature extremes, rainfall variability and timing in relation to 116 crop growth stages, crop physiological properties and response to water availability. Further, they are 117 confounded by differences in soil properties that determine water runoff and percolation (English et al., 118 2002). Among the above, rainfall variability (especially increased frequency of drought periods during 119 the growing season) can significantly impact productivity and profitability (Vico and Porporato, 2011).

\section{$120 \quad$ 1.1. Measuring water use efficiency at a farm level}

121 The vast majority of published research papers and reports on measuring water use efficiency focus on 122 engineering and agronomic techniques. Under this framework, water use efficiency can be defined as 123 the yield of harvested crop product achieved from the water available to the crop through rainfall, 124 irrigation and the contribution of soil storage (Singh et al., 2010). However, these approaches do not consider water as an economic good and therefore they do not allow the evaluation of the economic level of water use efficiency (Wang, 2010). The economic approach to

127 defining and measuring water use efficiency is based on the concept of input specific technical efficiency 
128 (Kaneko et al., 2004). Thus, water use at a farm level is used in combination with other inputs (land, 129 labour, fertilisers, etc.) to estimate a production frontier which represents an optimal allowance of the inputs used. This methodology aims to assess farmers' managerial capability to implement technological 131 processes (Karagiannis et al., 2003). In addition to management decisions, special regional 132 characteristics (i.e. soil type and its available water capacity) can play a crucial role in influencing water 133 application at farm level and therefore efficiency (Knox et al., 2012; Lilienfeld and Asmild, 2007).

134 In the literature there are broadly two approaches used to obtain efficiency estimates at a farm level; 135 parametric techniques (i.e. Stochastic Frontier Analysis (SFA)) and non-parametric techniques (i.e. Data 136 Envelopment Analysis (DEA)). Parametric techniques are used for the specification and estimation of a 137 parametric production function which is representative of the best available technology (Chavas et al., 138 2005). The advantage of this technique is that it provides the researcher with a robust framework for 139 performing hypothesis testing, and the construction of confidence intervals. However, its drawbacks lie 140 in the a priori assumptions in relation to the functional form of the frontier technology and the 141 distribution of the technical inefficiency term, in addition to the results being sensitive to the parametric 142 form chosen (Wadud and White, 2000).

143 Due to the flexibility of DEA, in avoiding a parametric specification of technology and assumptions about 144 the distribution efficiency but at the same time allowing for curvature conditions to be imposed, it is the 145 preferred method for the analysis of technical and specific input (water use) efficiency in the EARBC 146 over SFA. DEA is used to evaluate the performance efficiency of various Decision Making Units (DMU's) 147 which convert multiple inputs into multiple outputs. It is a technique that provides a straightforward 148 approach to measure the gap between each farmer's behaviour from best productive practices, which 149 can be estimated from actual observations of the inputs and outputs of efficient firms (Lansink et al., 150 2002; Wang, 2010). The production frontier is constructed as a piecewise linear envelopment of the observed data points. This means that the best performing farms are identified as those using the least

152 amounts of inputs to produce their individual levels of output. Linear, or convex, combinations of those 153 best performers constitute the production frontier. The efficiency of the farms is then measured relative 154 to this estimated frontier of best performers (Lilienfeld and Asmild, 2007). 
155 Various research projects have used DEA for measuring water use efficiency at a farm level in areas 156 where water use for irrigation is a critical issue in securing economic, social and environmental 157 sustainability like in Mauritania, Tunisia, South Africa and other parts of the world with relative dry 158 climate (Borgia et al., 2013; Chebil et al., 2012; Chemak, 2012; Frija et al., 2009; Lilienfeld and Asmild, 159 2007; Mahdi et al., 2008; Speelman et al., 2008; Veettil et al., 2011; Wang, 2010). The majority has used a sub-vector DEA model to estimate excess water use as proposed by Färe et al. (1994).

\subsection{Objectives}

162 There are two main objectives 1) to assess the technical efficiency of irrigating horticulture farms in 163 England and 2) to provide an estimate of water use efficiency at farm level. For these we use a 164 benchmarking technique with a sample of farms derived from the Farm Business Survey of 2009/2010. The identification of excessive water use at farm level can then be used to provide recommendations for improvements of management practices and policy interventions. In this research paper we consider water as an economic good and therefore an economic approach rather than an engineering approach is used to define and measure water use efficiency based on the concept of input specific technical efficiency. Excess water use has an economic impact (increased production costs) at a farm level but also can be a source of environmental degradation. In particular it not only reduces available water resources but also involves short and long term damage caused by surface runoff as a result of over application and deep percolation losses of water below the root zone which cannot be utilised by crops

173 (Pimentel et al., 2004). Further, farmers that over abstract and overuse surface or ground water from an aquifer that is not adequately recharging due to drought imposes an opportunity cost on future generations (Oster and Wichelns, 2003) and threatens the sustainability of the ecosystem.

176 For the purposes of the analysis, water use efficiency is defined as the ratio of the minimum feasible water use (based on the non-radial notion of input specific technical efficiency (Fang et al., 2013)) to the observed water use at a farm level for irrigation, subject to the available production technology, the

179 observed level of outputs and the use of other inputs (Matthews, 2013). It is therefore an input oriented measure of technical efficiency which allows for a radial reduction of water use at farm level (Wang, 
182 and the quantities of other inputs used. It is emphasised that in this sense, water use efficiency has an

183 economic rather than an engineering meaning (Kaneko et al., 2004; Wang, 2010).

184 The development and implementation of integrated water management strategies and policies becomes

185 a crucial decision to secure the sustainability of agricultural sector in specific parts of England (East 186 Anglia, South East). This suggests a need to develop guidance on what should be measured and how 187 data might be interpreted to demonstrate efficient use of water in agriculture (Knox et al. 2012).

188 Considering this we conclude on specific recommendations for the data requirements necessary to 189 measure water use efficiency at a farm level, based on the sub-vector efficiency approach. These are 190 discussed in the context of the sustainable intensification of agriculture and climatic change.

191 1.3. Determinants of efficiency

192 Water use efficiency in agriculture can be influenced by various factors as they have been identified in 193 the literature. Wang (2010) suggests that age, income, education level, farm size and the different 194 irrigation systems are factors influencing water use efficiency. Moreover, Wang (2010) identified that 195 exclusive water property rights as well as the competitive price mechanism had a strong influence in 196 efficiency. The same structure parameters as above were regressed at a second stage by Mahdi et al. 197 (2008), Lilienfeld and Asmild (2007) and Speelman et al. (2008). The latter, in addition, took into 198 consideration as an influencing parameter the choice of crop, the landownership and the total cultivated 199 area. The same approach was adapted by Wambui (2011) in the assessment of water use efficiency 200 and its influencing parameters in the Naivasha lake basin. Structural and managerial characteristics 201 were also proven to influence the technical performance of farms by Van Passel et al. (2007) who 202 concluded that the same factors as mentioned above as well as the prospect of succession and 203 dependency on subsidies are influencing efficiency. 


\section{2. Overview of the study area and data requirements}

205 Data for the empirical application of the model have been obtained from the Farm Business Survey ${ }^{3}$ 206 (FBS) which is a comprehensive and detailed database that provides information on the physical and 207 economic performance of farm businesses in England. The FBS uses a sample of farms that is 208 representative of the national population of farms in terms of farm type, farm size and regional location.

209 The FBS survey is carried out by the Rural Business Research and is the largest and most extensive 210 business survey of farms in England. It is commissioned by the Department for Environment, Food and 211 Rural Affair (DEFRA) and is also supported by the farming unions. There were in total 8,996 horticultural 212 businesses in England. However, approximately half of these are regarded as being too small for 213 inclusion in the FBS, as they fall below the minimum threshold. The sample size for 2009 cropping year 214 was 212 businesses. Out of those farms, 151 participated in the water use survey of the FBS with an average of 95 ha main crop area and an average of 26 ha irrigated area. Hence, farms with a percentage 216 of irrigated area over main crop area less than $90 \%$ were excluded from the sample. This criterion was

217 set in order to ensure that the sample contained only horticulture farms that rely their production on 218 irrigation. A sample of 74 Horticulture Farms was selected from the FBS 2009/2010 database. The 219 majority of the farms are based in EARBC ( 25 farms) followed by farms based in the catchment area of 220 South East (13 farms), Thames (9 farms), Humber (8 farms), South West (7 farms), Severn (7 farms), 221 North West (3 farms) and Northumbria (2 farms). The average water use for irrigation for the sample 222 is $2,710 \mathrm{~m}^{3} / \mathrm{ha}$.

223 In particular the $2009 / 2010$ cropping year could be characterised as a period with a series of events 224 strongly influencing both the area harvested and the growing conditions of crops. The 2009 spring was 225 characterised by generally cool, dry conditions which facilitated agricultural operations and reduced crop disease pressure. However the 2009 harvest period was wet which also increased the concern of fungal

\footnotetext{
${ }^{3}$ For further information about the Farm Business Survey, including data collection, methodology and Farm Business Survey results, please visit the Rural Business Research website: http://www.fbspartnership.co.uk/index.php?id=1528
} 
227 diseases in sugar beet and potatoes. Sugar beet harvest was disrupted by the exceptionally cold 228 conditions in January 2010 causing also problems for the transport of the product to the market 229 destinations. In regards to irrigation, substantially fewer farmers irrigated crops than held abstraction 230 licences for spray irrigation, due in part to the dry conditions of 2009. In addition, since DEA methods 231 are quite sensitive to the presence of outliers in the data when measuring efficiency (Sexton et al., 232 1986), eight farms were omitted from the initial sample, being identified as outliers based on the method 233 described in (Wilson, 1993, 2010). These outlier farms would have had a strong influence on the 234 construction of the benchmarking frontier and therefore could influence the results and the 235 interpretation of the efficiency scores. The final number of farms in the research sample was 66 . The 236 graphical method of Wilson (1993) is presented in detail on the online appendix of this paper. In total, 237 the sample includes 22 large, 24 medium and 20 small farms as well as 1 very small farm satisfying the 238 need to account for all different farm sizes ${ }^{4}$.

239 The horticulture farming systems ${ }^{5}$ were selected over other agricultural systems mainly because of three 240 reasons 1$)$ their contribution to UK agricultural output ( $£ 2,504$ million in 2009 and $£ 3,007$ million in $2412013), 2$ ) the demand of supplemented irrigation to secure yield (under drought conditions) and 3) 242 because it is one of the most representative agricultural systems in East Anglia and South East (areas 243 with high risk of drought and high demand for abstraction licences).

\footnotetext{
${ }^{4}$ In order to classify farms in the FBS into different sizes the Standard Labour Requirements (SLR) for different enterprises are calculated which are then used to find the total amount of standard labour used on the farm. Once the total annual SLR has been calculated the number of hours can be converted to an equivalent number of full time workers (on the basis that a full-time worker works a 39 hour week and so 1900 hours a year). This leads to the classification of farms by number of full time equivalent (FTE) workers as follows: Small farms: $1<\mathrm{FTE}<2$, Medium farms: $2<\mathrm{FTE}<3$, Large farms: $3<\mathrm{FTE}<5$

${ }^{5}$ Holdings on which fruit (including vineyards), hardy nursery stock, glasshouse flowers and vegetables, market garden scale vegetables, outdoor bulbs and flowers, and mushrooms account for more than two thirds of their total Standard Outputs (SOs) which are calculated per hectare of crops (FBS 2009-2010).
} 
244 The production technology for the estimation of technical and sub-vector efficiency was defined by the 245 total area farmed, total agricultural costs (including fertiliser, crop protection and seed costs), other

246 agricultural costs covering all costs with direct connection with crop production,energy costs including

247 fuel and electricity costs, total labour hours per year and water use for irrigation in cubic meters. The 248 data are aggregated at a farm level i.e. irrigation applications on different fields of the same farm are 249 aggregated into a single variable. The output used in the DEA model was the gross margin at a farm 250 level. The sample was selected in order to ensure the assumption of homogeneity in the DEA method.

251 Table 1 presents a description of the sample used to build the input and output DEA model.

\section{Methodology: Data Envelopment Analysis}

In an input orientated framework for $\mathrm{DEA}$, the best performing farms are identified as those that manage to produce the highest individual levels of output with the least amounts of inputs. Linear, or convex, combinations of those best performers constitute the production frontier. Since DEA is a benchmarking technique, the efficiency of the remaining farms is then measured relative to this estimated frontier of the best performers in the sample. A more detailed discussion of the different DEA models and the development of the techniques is available in (Cooper et al., 2007).

DEA models can be either input or output orientated assuming different types of returns to scale. For the purposes of this analysis an input orientated model with Variable Returns to Scale (VRS) was selected where efficiency scores indicate the total potential reduction for each input level while maintaining individual levels of outputs unchanged. VRS (Banker et al., 1984) are considered as the most appropriate in the case of agriculture (Asmild and Hougaard, 2006; Lilienfeld and Asmild, 2007). The alternative would have been to choose Constant Returns to Scale (CRS) assuming that when doubling all inputs, outputs will also double which is not a reasonable assumption in the case of agriculture. For example, a limiting production input is area farmed which is difficult to increase especially in the short run.

Furthermore, since the purposes of this research is to assess the inefficiency of water use for GCFs in the EARBC, a non-discretionary or sub-vector variation of the model for DEA was used. 
270 To formalise the above let us assume that we observe a set of $n$ farms and each farm $i=\{1, \ldots, n\}$ has 271 a set of inputs and outputs representing multiple performance measures. Considering then that each 272 farm $i$ uses $J(j=1, \cdots, J)$ inputs, $x_{j}$ to produce $s$ outputs $y_{r}(r=1, \cdots, s)$. 
273 The general form of an input oriented DEA linear programming with all inputs variable is as follows:

$$
\begin{gathered}
\min _{\theta, \lambda^{i}} \theta^{\prime} \\
\text { s.t. } \quad \theta x^{\prime}{ }_{j i} \geq \sum_{i=1}^{n} \lambda^{i} x_{j i} \\
y_{r i}^{\prime} \leq \sum_{i=1}^{n} \lambda^{i} y_{r i} \\
\lambda^{i} \geq 0 \\
\sum_{i-1}^{n} \lambda^{i}=1
\end{gathered}
$$

274 Where $\theta^{\prime}$ is a scalar, representing the efficiency score for each of the $n$ farms. The estimate will satisfy 275 the restriction $\theta_{i^{\prime}} \leq 1$ with the value $\theta_{i^{\prime}}=1$ indicating an efficient farm. This is because the ratio is 276 formed relative to the Euclidean distance from the origin over the production possibility set.

277 Also, in the above formulation we consider that there is a set of discretionary or variable inputs $D I$, $278 D I \subset\{1, \cdots, J\}$ and a set of non-discretionary inputs $N D I, N D I=\{1, \cdots, F\} \backslash D I=\{h \in\{1, \cdots, J\} \mid h \notin$ $279 D I\}$ that cannot be adjusted or are held fixed at least in the short run. The combination of the DI and 280 NDI variables defines therefore the technology set P:

$$
P=\left\{\left(x_{D I j i}, x_{N D I j i}, y_{r i}\right) \mid x_{D I j i} \text { and } x_{N D I j i} \text { can produce } y_{r i}\right\}
$$

281 As suggested by Bogetoft and Otto (2010) in cases where DI and NDI variables exist, a traditional and 282 popular variation of the Farrell (1957) procedure is used to solve the linear DEA programme with respect 283 to the largest proportional reduction in the DI variables alone.

$$
\theta\left(\left(x_{D I j i}, x_{N D I j i}, y_{r i}\right) ; P\right)=\min _{\theta}\left\{\theta \mid\left(\theta x_{D I j i}, x_{N D I j i}, y_{r i}\right) \in P\right\}
$$


285 The linear DEA programme can therefore be modified as follows where only the DI variables are 286 reduced. Thus the irrigation, water use specific DEA efficiency score for observation $x^{\prime}, \theta^{\prime}$, is estimated 287 by the following linear programming (LP) problem:

$$
\begin{aligned}
& \min _{\theta, \lambda^{i}} \theta^{\prime} \\
& \text { s.t. } \quad \theta x_{D I j i}^{\prime} \geq \sum_{i=1}^{n} \lambda^{i} x_{D I j i} \quad j \in D I \\
& x^{\prime}{ }_{N D I j i} \geq \sum_{i=1}^{n} \lambda^{i} x_{N D I j i} \quad j \in N D I(i i) \\
& y_{r i}^{\prime} \leq \sum_{i=1}^{n} \lambda^{i} y_{r i} \\
& \lambda^{i} \geq 0 \\
& \sum_{i-1}^{n} \lambda^{i}=1
\end{aligned}
$$

288 In order to enable the solution of the above model, the DEA linear programming can be rewritten in the 289 following form where fixed or non-discretionary inputs are treated as negative outputs in a input based 290 mode (Bogetoft and Otto, 2010):

$$
\begin{aligned}
& \min _{\theta, \lambda^{i}} \theta^{\prime} \\
& \text { s.t. } \quad \theta x_{D I j i}^{\prime} \geq \sum_{i=1}^{n} \lambda^{i} x_{D I j i} \quad j \in D I \\
& -x_{N D I j i}^{\prime} \geq \sum_{i=1}^{n} \lambda^{i}\left(-x_{N D I j i}\right) \quad j \in N D I(i i) \\
& y_{r i}^{\prime} \leq \sum_{i=1}^{n} \lambda^{i} y_{r i} \\
& \lambda^{i} \geq 0 \\
& \sum_{i-1}^{n} \lambda^{i}=1
\end{aligned}
$$

291 Where, $x_{D I j i}$ is the $j^{\text {th }}$ discretionary input for farm $i, x_{N D I j i}$ is the $j^{\text {th }}$ non-discretionary input for farm $i$ 292 and $y_{r i}$ is the $r^{\text {th }}$ output for farm $i, i=(1, \cdots n), j=(1, \cdots m)$ and $r=(1, \cdots s)$. The optimal value $\theta$ 293 represents the sub-vector efficiency score for each farm and its values lie between 0 and 1 . This 294 efficiency score indicates how much a farm is able to reduce the use of its discretionary inputs (water 295 use) without decreasing the level of outputs with reference to the best performers or benchmarking 296 farms in the sample. The first two constraints limit the proportional decrease in both discretionary 297 (equation-5 $\mathbf{( i )}$ ) and non-discretionary (equation- $\mathbf{5}_{(i i)}$ ) inputs, when $\theta$ is minimised in relation to the 298 input use achieved by the best observed technology. The third constraint ensures that the output 299 generated by the $i^{\text {th }}$ farm is less than that on the frontier. All three constraints ensure that the optimal 
300 solution belongs to the production possibility set. The final constraint expressed by the equation $\mathbf{5}_{(i v) \text {, }}$

301 called also the convexity constraint, ensures the VRS assumption of the DEA sub-vector model.

302 Therefore, the non-discretionary inputs can be treated in the DEA model as negative outputs (Bogetoft

303 and Otto, 2010). The CRS and VRS models differ only in that the former, but not the latter includes the

304 convexity condition described by equation $\mathbf{5}_{(i v)}$ and its constraints in $\mathbf{5}_{(v)}$ (Cooper et al., 2007).

305 Considering the above, a farm that receives a sub-vector efficiency score equal to 1 is therefore a best

306 performer located on the production frontier and has no reduction potential for water use. Hence, and

307 since DEA is a benchmarking method, the farms with a sub-vector efficiency score equal to 1 will define

308 the optimal water use at farm level. The efficiency score of the remaining farms in the sample is then

309 measured relative to the farms defining the efficiency frontier (optimal water use). Any other score less

310 than $\theta=1$ indicates a potential reduction in water use, i.e. excess water is used at a farm level, thus

311 this farm is considered as water use inefficient. To illustrate this with a numerical example let us assume

312 that the optimal $\theta$ for a farm is 0.75 which means that this farm is able to produce the same level of

313 output by using $75 \%$ of its current level of water (or reducing water use by $25 \%$ ) when compared to

314 the best performing technology in the sample. The excess water use can be calculated as:

$$
(1-\theta) x_{D I j i}
$$

where $\theta$ is the sub-vector efficiency score, 1 identifies the optimal input, output ratio and $x_{D I j i}$ is the 316 amount of water use at a farm level.

317 To illustrate better the difference between the sub-vector and the conventional DEA model we assume

318 a two input one output case presented in Figure 1. The problem takes the $i^{\text {th }}$ farm $\mathrm{A}$ and then seeks to 319 radially contract the input vector, $x_{i}$, as much as possible, while remaining within the feasible input set.

320 The inner-boundary of this set is a piecewise linear isoquant determined by the frontier data points (the efficient farms in the sample are F1 and F2). The radial contraction of the input vector $x_{i}$ produces a 322 projected point on the frontier surface $\left(A^{0}\right)$.

323 This projected point is a linear combination of the observed data points, with the constraints ensuring that the projected point cannot lie outside the feasible set. The overall technical efficiency measure of 325 farm A relative to the frontier is given by the ratio $\theta=0 A^{0} / 0 A$. In the case of measuring the sub-vector 
efficiency for input $X_{1}$ (water use), then water use $\left(X_{1}\right)$ is reduced while holding $X_{2}$ (all the remaining inputs - agricultural crop production costs, area farmed, energy costs, etc.) and output (Gross Margin) constant. In the graph $A$ is projected to $A^{\prime}$ and sub-vector efficiency is given by the ratio $\theta^{\prime}=0^{\prime} A^{\prime} / 0^{\prime} A$.

\subsection{The impact of the size of economies of scale on the productivity of the farm}

The DEA model under the VRS assumption decomposes technical efficiency into pure technical efficiency (PTE) and scale efficiency (SE) (Färe et al., 1994). Therefore, by estimating technical efficiency scores under assumptions of CRS (TECRS) - known as a measure of overall technical efficiency (OTE) - and VRS (TEvRs) one can measure the SE which measures the impact of scale size on the productivity of the farm. SE efficiency is therefore defined as follows:

$$
S E=\frac{T E_{C R S}}{T E_{V R S}}
$$

$S E$ can take values between 0 and 1 . When $S E=1$ a farm is operating at optimal scale size and otherwise if $S<1$. The information revealed by $S E$ is used to indicate potential benefits from adjusting farm size. Furthermore, expression (7) can be used to decompose TE $\mathrm{CRS}_{\text {ins }}$ into two mutually exclusive and non-additive components, the pure technical efficiency (PTE) (estimated by the VRS specification) and $S E$

$$
T E_{C R S}=T E_{V R S} * S E
$$

This allows insight into the source of inefficiencies. The $T E_{V R S}$ of water use specifies the possible efficiency improvement that can be achieved without altering the scale of operations. Hence it is considered as a measure of the required reduction in water use to improve efficiency and management of water resources in the short run. On the other hand, the $T E_{C R S}$ and $S E$ measures require the farm to increase or decrease its scale of operation and therefore should be viewed as long run measures that aim to reduce water use for the long run improvement in efficiency.

One shortcoming of the measurement of $S E$ is that when $S E<1$ it is difficult to indicate whether the farm operates in an area of Increasing Returns to Scale (IRS), Decreasing Returns to Scale (DRS) or Constant Returns to Scale (CRS). For that reason a detailed analysis and discussion of the nature of Returns to Scale (RTS) is required. The nature of RTS is determined by the relationship of the proportion of inputs used to produce the output for a farm. Whether IRS, DRS or CRS prevail depends on the 
351 relationship between the proportional change of inputs and outputs (Varian H., 2010). This shortcoming

352 can be bypassed if an additional DEA problem with non-increasing returns to scale (NIRS) is imposed.

353 This can easily be achieved by substituting the $\sum_{i-1}^{n} \lambda^{i}=1$ restriction in equation (5) with $\sum_{i-1}^{n} \lambda^{i} \leq 1$

354 and then calculating the relevant technical efficiency (TENIRS). According to Färe et al. (1985), these

355 three estimated frontiers under CRS, VRS, and NIRS can be used to identify the returns to scale

356 characteristics of the technology at any given point. Specifically, a) if $T E_{C R S}=T E_{N I R S}<T E_{V R S}$, the input-

357 oriented projection of the VRS frontier is under increasing returns to scale b) if $T E_{V R S}=T E_{N I R S}>T E_{C R S}$,

358 diminishing returns hold and c) constant returns to scale hold if and only if $S E=1=T E_{C R S}=T E_{N I R S}=$ $359 T E_{V R S}$.

$360 \quad 3.2$ Econometric estimation of drivers of water use efficiency

361 Beyond the analysis of water use efficiency levels for each farm, a truncated regression model at a 362 second stage was used to assess the impact of various managerial characteristics on the level of 363 efficiency.

364 The hypotheses to be tested via these variables are the following:

365 A set of management practices and irrigation methods will have a positive impact into reducing water 366 use inefficiency (reducing distance function to the DEA efficiency frontier) and will improve the 367 performance and productivity of horticulture farms. In particular:

368 a) The establishment and use of rainwater collection systems will both have a positive economic impact 369 (reduce cost of water) and will also have a positive environmental impact since it will reduce the volume 370 of ground or surface water abstracted

371 b) A positive impact is assumed for the use of in-field soil moisture measurements (including feeling 372 soil, crop inspection), the use of water balance calculations and the use of a decision support tool since 373 these management practices will allow for the application of precision irrigation at a farm level

374 c) Moreover, the positive impact of the following irrigation systems and application is assumed; i) use 375 of an irrigation system characterised as trickle/drip/spray, ii) use of a drip irrigation system iii) use of 376 an overhead irrigation system iv) combinations of those. 
377 d) Finally, the last assumption to be tested is the impact of optimising the irrigations systems used by

378 the farmers or not.

379 Following the above description of the variables, the following econometric model is estimated:

Where, WUEff is the biased corrected water use efficiency $(0<$ WUEff $<1)$, RcollSyst, InFieldM, WatBalCal, DecSuppT, Recycl and OptIrrigSystem are dummy variables of the management practices for efficient water use at a farm level $(1=$ the management practice is applied, $0=$ Otherwise i.e. no management practice is applied). The OtherSyst, Drip, Overh, DripOverh, TrickOverh, DripTrick and DripTrickOver are also dummy variables of the irrigation systems used at a farm level $(1=$ the irrigation system is used, $0=$ Trickle Spray irrigation systems only). The descriptive statistics of the explanatory variables are presented in Table 2. In particular, OtherSyst variable refers to farms using (boom, rain gun and centre pivots or linear moves irrigation systems), Drip variable includes farms using only drip irrigation systems and Overh variable only overhead irrigation systems. Moreover, 4 dummy variables are used to express the use of combinations of irrigation systems: DripOver - Use of drip and overhead irrigation systems, TrickOverh - Use of trickle spray and overhead irrigation systems, DripTrick - Drip and Trickle irrigation systems and finally the DripTrickOver variable represents farms in the sample using a combination of the three aforementioned irrigation systems. The reference group used in the truncated regression is farms using Trickle Spray irrigation systems only.

Studies measuring productivity and efficiency using DEA to investigate the impact of environmental factors at a second stage analysis have suffered from two problems. 1) serial correlation among the DEA estimates and 2) correlation of the inputs and outputs used in the first stage with second-stage environmental variables (Simar and Wilson, 2007). A solution to these problems consists of bootstrapping the results to obtain confidence intervals for the first stage productivity or efficiency scores (Simar and Wilson, 1998, 2007).

The significance of the Simar and Wilson (2007) double bootstrap procedure derives from the bias corrected efficiency estimation of $\theta^{\prime}$ (estimated by expression (5)). These estimates are used as 
parameters in a truncated regression model. The selection of the model was based on the fact that the outcome variable is restricted to a truncated sample of a distribution. Since the dependent variable can take values between zero and one, we have a left truncation of the sample $(0 \leq$ biased corrected water use efficiency). It must be noted that a censored model (e.g. Tobit) would not have been appropriate in this case since water use efficiency data have the characteristics of truncated data - limited in the sample of interest. Furthermore, according to Simar and Wilson (2007) and Banker and Natarajan

411 (2008) Tobit estimation in the second stage yields biased and inconsistent estimators. The main reason

412 for the selection of the truncated model by Simar and Wilson (2007) is that the true efficiency estimates

413 are unobserved and are replaced with DEA estimates of efficiency. A detailed presentation of the double 414 bootstrapped procedure and the Algorithm 2 used in this paper is available in Simar and Wilson (2007) 415 and also on the online appendix of the paper.

\section{4. Results}

417 The estimated mean of technical efficiency under the two different assumptions of VRS (PTE) and CRS 418 (OTE) for the sample of irrigating horticulture farms was $0.85(\mathrm{STD}=0.20)$ and $0.74(\mathrm{STD}=0.28)$ 419 respectively. This implies that the irrigating farms in the sample could on average reduce their inputs 420 by $15 \%$ without any size adjustments (PTE is considered) and by $26 \%$ when size adjustments are made 421 (OTE is considered), maintaining in both cases the same level of output. Table 3 presents statistical 422 information and the distribution of PTE and OTE for the sample. The mean SE is $0.86(\mathrm{STD}=0.22)$ with $42340 \%$ of the farms operating at their optimal scale (SE=1).

424 The mean sub-vector efficiency is $0.51(\mathrm{STD}=0.44)$ under the assumption of CRS (OTE), indicating that 425 the observed value of outputs (Gross Margin) could have been maintained by keeping the level of other 426 inputs constant whilst reducing water requirements by $49 \%$. In addition, when VRS (PTE) are assumed 427 the mean sub-vector efficiency for the horticulture farms in the sample is $0.65(S T D=0.41)$ indicating a 428 reduction in water requirements by $35 \%$. Table 4 presents the relationship between technical efficiency 429 estimated by the conventional model (all inputs are discretionary) and the sub-vector model (water use 430 is a discretionary input and the remaining inputs are considered as non-discretionary). Savings in water 431 use were estimated through expression (6) by taking into consideration also the difference in technical 
432 and sub-vector efficiency estimates. In the case of medium and small size farms, water savings are

433 estimated to $533 \mathrm{~m}^{3} / \mathrm{ha}$ in average, while for large size farms this can be more than $1000 \mathrm{~m}^{3} / \mathrm{ha}$.

434 When returns to scale are considered in the analysis, $40 \%$ of the farms in the sample operate under

435 constant returns to scale indicating that these farms are not required to adjust their scale of operation

436 in order to improve efficiency in the long run. However, $18 \%$ of the irrigating horticulture farms are

437 operating under DRS which imply a reduction in scale of operation in order to achieve input use efficiency

438 and $47 \%$ of the farms are operating under IRS. The latter indicates that these farms need to shift down

439 their long-run average cost curve and increase their size of operation in order to save costs (develop

440 long term economies of scale). Table 5 presents information in relation to the returns to scale and farm

441 size in the sample. It is interesting to note that a significant proportion of medium and small farms

442 operate under IRS which implies that these farms can potentially increase output; and this increase will

443 be proportionally greater than a simultaneous and equal percentage change in the use of inputs,

444 resulting in a decline in average costs.

\section{4.1. The econometric estimation of water use efficiency determinants}

446 The average bias corrected water use efficiency (robust DEA estimate of efficiency) for the 62 irrigating

447 horticulture farms in the sample was $0.40(S T D=24)$, while the average ordinary water use efficiency

448 was 0.65 . We need to note that for the second stage of the analysis, four farms were excluded from

449 the sample since no irrigation systems or practices could be identified for them (no information was

450 available in the FBS dataset).

451 Table 6 presents a summary of the results of the double bootstrapped truncated regression model

452 following the method of Simar and Wilson (2007). It needs to be emphasised that the dependent 453 variable in the model is the vector of the reciprocal of DEA estimate (distance function), estimated for 454 the input oriented, variable returns to scale water use efficiency model. Hence, it measures inefficiency. 455 The objective will be to minimise the distance to the frontier and therefore, the sign of the parameters 456 with a positive impact on water use efficiency must be also positive. From the initial results it can be 457 stated that the model is a good fit with the data (Wald Chi-square $=40.17, \mathrm{P}<0.001$ ). 
458 In terms of water use efficiency management practices at a farm level, the assumption that recycling 459 water could have a positive impact on water use efficiency is sustained from the results since it is 460 positive and significant at $0.05 \%$ level $\left(\beta_{5}=0.26, p-\right.$ value $\left.<0.05\right)$. For farmers with installed 461 recycling water systems the predicted sub-vector water use efficiency score will increase by 0.26 . 462 Significant and also positive impact in increasing water use efficiency at a farm level has also the use of 463 a decision support tool for irrigation $\left(\beta_{4}=0.24, p-\right.$ value $\left.<0.05\right)$. The assumption that farmers 464 improve their water use efficiency by using in-field soil moisture measurement, water balance 465 calculations, rainwater collection systems and an optimised irrigation systems is not sustained by the 466 results.

467 In terms of irrigation systems used, our results indicate that the trickle/drip/spray lines irrigation system 468 has a positive impact towards improving water use efficiency. In particular, the use of other irrigation systems (boom, rain gun and centre pivots or linear moves) when compared to the use of only trickle 470 spray irrigation systems reduce water use efficiency by $0.25\left(\beta_{7}=-0.25, p-\right.$ value $\left.<0.01\right)$. Similar 471 negative impact to water use efficiency is observed for drip and overhead irrigation systems with a 0.43 $472\left(\beta_{8}=-0.43, p-\right.$ value $\left.<0.05\right)$ and $0.22\left(\beta_{9}=-0.22, p-\right.$ value $\left.<0.01\right)$ reduction in sub-vector 473 efficiency when compared to the use of only trickle spray irrigation systems by the farmers.

474 Moreover, the combination of trickle and overhead irrigation systems with the use of only trickle spray 475 irrigation systems will also have a statistically significant and negative impact by reducing water use 476 efficiency by $0.41\left(\beta_{11}=-0.41, p-\right.$ value $\left.<0.05\right)$. Any other combination of management practices as 477 it is observed in Table 6 will have not statistically significant impact to water use efficiency.

\section{5. Discussion and implications}

479 The increased frequency of extreme weather phenomena (drought and flood periods) in the future for 480 the UK will result to a higher risk with regards to securing yield and farm income. This, in addition to 481 increased food demand, has raised the need for agricultural production systems to adapt in a challenging 482 and insecure environment. Agriculture in the EARBC and also in the South East of England is vulnerable 483 to water shortages due to the increasing risk of drought and over abstraction of water resources. In 484 addition, considering the substantial financial benefits for irrigation, especially for high value crops and 
vegetables, any distortions in the supply of water for irrigation will have a significant impact on farmers' income. Therefore the efficient use of water resources becomes a joined priority within the framework of SI of agriculture which requires a sustainable end efficient management of natural resources.

488 The average sub-vector efficiency score of 0.65 for irrigating horticulture farms suggests that 489 improvements can be made towards the management of water resources in agriculture. The generally prevailing dry conditions of the $2009 / 2010$ production year increased the demand for water resources and this can partly explain the excess of water use in the sample. Especially when areas such as the East Anglia and the South East of England are considered as two of the highest risk of drought areas in the country.

Regarding returns to scale, pathways for the improvement of productivity and maximisation of net benefits given the limited land and water resources are suggested. Specifically, $47 \%$ of the farms operate on the downward sloping part of the long run average cost curve. There is a potential therefore to increase production and hence profitability. This information, in addition to the results derived from the PTE analysis; indicate also a need for change in the management of inputs in the short run in order to improve control over the production process. On the other hand $18 \%$ of the farms are either

500 producing above their profit maximising level of outputs or using excessive amounts of inputs per unit of output. The latter is confirmed by the level of inefficiency of water use based on the sub-vector model 502 (Table 3).

Around $36 \%$ of the farms in the sample are abstracting water directly from bore holes, river streams, ponds, lakes and reservoirs. Irrigation water demand for the remaining $70 \%$ of the farms is supplied by water companies. The average cost of water supplied for irrigation by water companies is $£ 2.59 / \mathrm{m}^{3}$

$506(\mathrm{STD}=5.55$, Trimmed Median $=£ 1.13)$. According to the results presented in Table 4 , the average 507 potential savings in cost of water used for irrigation that can be achieved is $649 \mathrm{f} / \mathrm{farm}$ in a year. Hence, 508 the adoption of efficient water recycling systems as these are identified by the results of the second 509 stage regression analysis of this paper and the use of a decision for irrigation support tool can potentially 510 reduce significantly input costs and also improve production efficiency. The installation and use of a recycling water systems can increase water use efficiency score by 0.26 . 
512 The use of a rainwater harvesting system to supply water for irrigation was not found as a management

513 system with a statistically significant impact on water use efficiency. The reason for the low adoption of

514 rainwater harvesting systems is that currently cannot compete financially with direct abstraction or

515 mains supply but it can potentially be considered as an area for future development in UK irrigated

516 farming systems (Weatherhead et al., 1997). Farms that adopt rainwater harvesting systems could

517 potentially reduce mains water consumption, and hence input cost, and also to reduce their

518 environmental impact. Further research is required to explore the full potential of the installation of

519 rainwater harvesting systems in irrigation farming systems in England.

520 In order to renew their abstraction licences farmers are required to demonstrate efficient use of water

521 resources to the regulator (Environment Agency, 2013). The results from the sub-vector model confirm

522 that almost half of the farms (53\%) in England are on the frontier and hence avoid any excess in water

523 use when compared with peer farms in the sample. Knox et al. (2012) refers to the "Save water, save

524 money ${ }^{6 \prime}$ booklet produced in 2007 and distributed to 2500 farmers across England to promote the

525 "pathway to efficiency". The main components of the pathway include that farmers understand their

526 system of production, make efforts to optimise the use of their irrigation systems, ensure appropriate

527 soil and water management and demonstrate best practices that have proved over time to lead to more

528 efficient irrigation (Knox et al., 2012).

529 The profile of the best performing irrigating farms in our sample resulting from the study of the farms

530 on the frontier can be used as a good practice example to promote water use efficiency in England. The

531 installation and use of a trickle/drip/spray lines irrigation system as it was shown by the results of the

532 second stage analysis can increase water use efficiency when compared to other irrigation systems used

533 by the sample. The spray type trickle irrigation systems have the advantage that are less likely to clog

534 when compared to subsurface and drip systems, can improve crop yields and reduce water use and

535 energy consumption at a farm level (James, 1988). These irrigation systems belong to the general

\footnotetext{
${ }^{6}$ The information booklet is available for download from the UK Irrigation Association website: http://www.ukia.org/pdfs/Save\%20water\%20save\%20money.pdf
} 
536 category of micro-irrigation systems that include various low rate emission devices such as drip 537 irrigation, subsurface irrigation, bubbler irrigation and many other. However, on the other hand the use

538 of drip irrigation systems by the farms on the sample had a negative impact on water use efficiency.

539 The use of efficient irrigation systems has the potential to reduce environmental risks due to leakages 540 and excess of nutrients which could damage biodiversity and water quality. In addition, these systems 541 could be also used for fertiliser application in the field. Moreover, spray type trickle irrigation can be 542 used to maintain the water content of the root zone near the optimal level and hence, improve 543 productivity (Mays, 2010).

544 In comparison to the trickle/drip/spray line irrigation systems, the use of an overhead sprinkle irrigation 545 system has a statistically significant negative impact on water use efficiency. In particular it reduces the 546 level of water use efficiency by 0.22 . Although overhead sprinkle irrigation systems can improve the 547 efficiency of crop development and water application due to the uniformity in water distribution, it is 548 also a high and continuous energy demanding system which under poor weather conditions (strong 549 wind and high temperature) increases the potential for water use excess and inefficiency.

550 The two management practices with a positive and statistically significant impact on improving water 551 use efficiency are the use of a decision support tool and recycling water used. The use of a decision 552 support tool for short and long term irrigation planning and monitoring has a positive impact into 553 reducing water use inefficiency and hence pushing the farms towards the frontier. Such a tool could 554 potentially provide farmers with options to support management decisions to improve economic and 555 water efficiency as well as the environmental performance (reducing wastage) of the farming system 556 (Khan et al., 2010).

557 Furthermore, in-field soil moisture measurement (including assessing the soil and crop inspection) and 558 water balance calculations are management practices applied by the peer farms which enable them to 559 schedule irrigation better and hence provide the optimal application of water at the right time and 560 volume. However, these have no statistically significant impact on water use efficiency.

561 Furthermore, as it was shown from the regression analysis the set of water use efficiency irrigation 562 management practices and systems with a positive and statistically significant impact on water use 
563 efficiency (recycling water, decision support tool and the use of trickle/drip/spray lines irrigation

564 systems) can be an effective strategy to reduce runoff and significantly contribute to the reduction of 565 diffuse pollution which is in line to the findings of the MOPS2 project (Deasy et al., 2010). Such practices

566 will improve water quality and also enable UK agriculture to meet the requirements of the EU water 567 framework directive.

\section{6. Conclusions}

569 Water for agriculture in the EARBC, in the South East of England and in other regions of the country 570 may be becoming scarcer and more variable due to the increased abstraction rates and the increased 571 occurrence of drought phenomena during the crop development period. Nationally there is a need to 572 secure production in order to meet increasing food demand and thus supplementary irrigation of crops 573 increases the pressure on water resources in water catchments across England. To ensure the 574 sustainability of farming systems in the area, farmers need to both maximise economic productivity and 575 efficiency while directing their strategies towards minimising excess of water for irrigation and other 576 agricultural uses (washing, spraying).

577 A benchmarking technique such as DEA can provide a useful tool to identify excess water use when 578 comparing farms with others in the same region and with the same characteristics and therefore help 579 to improve water use efficiency at farm level. Moreover, peer farms (farms on the frontier) can provide 580 useful information in respect of operational and management changes that can be made to improve 581 irrigation system performance and water productivity. In addition, the analysis on returns to scale 582 provides pathways for long term improvements and planning which could be used to strategically 583 position a farm in relation to the long term average cost curve and hence improve economic efficiency 584 and productivity.

585 From a policy perspective, the current water abstraction regulation in the UK is under reform. The main 586 pillars of the reform are based on the need to face challenges in water availability due to changing 587 weather conditions, the increased demand for water from growing population and the need to enable 588 trading of water rights (Defra, 2013). Our results suggest that the new legislation should incentivise 589 farmers to improve management practices for efficient water for irrigation and also improve water 
590 storage at farm level through rain harvesting and on farm reservoirs. Furthermore, it is essential that 591 any reform accounts for the importance of supplementary irrigation for cash crops (potatoes, sugar 592 beet) and the need to secure yield. Any restriction on water abstraction during the growth period due 593 to water shortages or drought conditions would result to failure in meeting quality standards and 594 consequently income loss to farmers. Therefore, it is important that the new regime considers the 595 economic significance off irrigated agriculture not only for the farming systems but also for the local 596 jobs and local economies. 


\section{Acknowledgments}

598 The authors wish to thank the University of Reading for funding this research and also the Agriculture, 599 Food and Investigation Team of the University of Reading for providing technical assistance and 600 guidance over the use of FBS data. Special thanks go to two anonymous reviewers that with their 601 constructive comments helped us to improve the final manuscript.

602

603

pg. 27 
605

606

607

608

609

610

611

612

613

614

615

616

617

618

619

620

621

622

623

624

625

626

627

628

629

630

631

632

633

634

635

636

637

638

639

640

641

642

643

644

645

646

647

648

649

650

651

652

653

654

655

656

657

658

Asmild, M., Hougaard, J.L. (2006). Economic versus environmental improvement potentials of Danish pig farms. Agricultural Economics, 35(2), 171-181. doi: http://dx.doi.org/10.1111/j.1574-0862.2006.00150.x Banker, R.D., Charnes, A., Cooper, W.W. (1984). Some Models for Estimating Technical and Scale Inefficiencies in Data Envelopment Analysis. Management Science, 30(9), 1078-1092. doi: http://dx.doi.org/10.1287/mnsc.30.9.1078

Banker, R.D., Natarajan, R. (2008). Evaluating Contextual Variables Affecting Productivity Using Data Envelopment Analysis. Operations Research, 56(1), 48-58. doi: http://dx.doi.org/10.1287/opre.1070.0460 Bogetoft, P., Otto, L., 2010. Benchmarking with DEA, SFA, and R. Springer, New York.

Borgia, C., García-Bolaños, M., Li, T., Gómez-Macpherson, H., Comas, J., Connor, D., Mateos, L. (2013). Benchmarking for performance assessment of small and large irrigation schemes along the Senegal Valley in Mauritania. Agricultural Water Management, 121(0), 19-26. doi:

http://dx.doi.org/10.1016/j.agwat.2013.01.002

Charlton, M., Bailey, A., Arnell, N., 2010. Water for Agriculture - Implications for Future Policy and Practice: Reviewing and modelling the impacts of climate change in future food production. Royal Agricultural Society of England.

Chavas, J.P., Petrie, R., Roth, M. (2005). Farm household production efficiency: Evidence from The Gambia. American Journal of Agricultural Economics, 87(1), 160-179. doi: http://dx.doi.org/10.1111/j.00029092.2005.00709.x Chebil, A., Frija, A., Abdelkafi, B. (2012). Irrigation water use efficiency in collective irrigated schemes of Tunisia: determinants and potential irrigation cost reduction. Agricultural Economics Review 13(1), 39-48. doi: http://www.eng.auth.gr/mattas/13 1 3.pdf

Chemak, F. (2012). The Water Demand Management by Monitoring the Technology Performance and the Water Use Efficiency. American Journal of Environmental Sciences, 8(3), 241-247. doi:

http://dx.doi.org/10.3844/ajessp.2012.241.247

Chen, Y., Du, J., Huo, J. (2013). Super-efficiency based on a modified directional distance function. Omega, 41(3), 621-625. doi: http://dx.doi.org/10.1016/j.omega.2012.06.006

Cooper, W., Seiford L. M, Tone K., 2007. Data Envelopment Analysis. A Comprehensive Text with Models, Applications, References and DEA-Solver Software Second Edition ed.

Daccache, A., Weatherhead, E.K., Stalham, M.A., Knox, J.W. (2011). Impacts of climate change on irrigated potato production in a humid climate. Agricultural and Forest Meteorology, 151(12), 1641-1653. doi: http://dx.doi.org/10.1016/j.agrformet.2011.06.018

Deasy, C., Quinton, J.N., Silgram, M., Stoate, C., Jackson, R., Stevens, C.J., Bailey, A.P. (2010). Mitigation Options for Phosphorus and Sediment (MOPS): Reducing Pollution in Runoff from Arable Fields. The Environmentalist(180), 12-17. doi: http://oro.open.ac.uk/id/eprint/25494

Defra, 2009. Adapting to Climate Change: UK Climate Projections, in: Department for Environment Food \& Rural Affairs (Ed.). Defra, London.

Defra, 2011. Water Usage in Agriculture and Horticulture. Results from the Farm Business Survey 2009/10 and the Irrigation Survey 2010, in: Department for Environment Food \& Rural Affairs (Ed.). National Statistics.

Defra, 2013. Making the most of every drop: Consultation on reforming the water abstraction system, in: Affairs, D.f.E.F.R. (Ed.). Defra, London.

English, M.J., Solomon, K.H., Hoffman, G.J. (2002). A paradigm shift in irrigation management. Journal of Irrigation and Drainage Engineering-Asce, 128(5), 267-277. doi: http://dx.doi.org/10.1061/(Asce)07339437(2002)128:5(267)

Environment Agency. (2008). Water resources in England and Wales - current state and future pressures. Bristol: Environment Agency.

Environment Agency.(2011). The case of change-current and future water availability. Bristol: Environment Agency, 41.

Environment Agency. (2013). Managing water abstraction. Bristol: Environment Agency, 29.

Fang, H.-H., Lee, H.-S., Hwang, S.-N., Chung, C.-C. (2013). A slacks-based measure of super-efficiency in data envelopment analysis: An alternative approach. Omega, 41(4), 731-734. doi:

http://dx.doi.org/10.1016/j.omega.2012.10.004

FAO, 2011. Save and Grow: A policymaker's guide to the sustainable intensification of smallholder crop production. Food and Agriculture Organization of the United Nations, Rome. 
659 Färe, R., Grosskopf, S., Lovell, C.A.K., 1985. The Measurement of Efficiency of Production. Springer.

660 Färe, R., Grosskopf, S., Lovell, C.A.K., 1994. Production frontiers. Camridge University Press, Cambridge.

661 Farrell, M.J. (1957). The Measurement of Productive Efficiency. Journal of the Royal Statistical Society. Series A

662 (General), 120, 253-290. doi: http://dx.doi.org/10.2307/2343100

663 FAS, 2013. Cutting farm costs by improving water use efficiency, in: Farming Advice Service (Ed.).

664 Department for Environment, Food and Rural Affairs.

665 Frija, A., Chebil, A., Speelman, S., Buysse, J., Van Huylenbroeck, G. (2009). Water use and technical

666 efficiencies in horticultural greenhouses in Tunisia. Agricultural Water Management, 96(11), 1509-1516.

667 doi: http://dx.doi.org/10.1016/j.agwat.2009.05.006

668 Garnett, T., Godfray, C., 2012. Sustainable intensification in agriculture. Navigating a course through

669

670

671

672

673

674

675

676

677

678

679

680

681

682

683

684

685

686

687

688

689

690

691

692

693

694

695

696

697

698

699

700

701

702

703 competing food system priorities. Food Climate Research Network and the Oxford Martin Programme on the Future of Food, University of Oxford, UK.

James, L.G., 1988. Principles of farm irrigation systems design. John Wiley and Sons Limited.

Jenkins, G., Murphy, J., Sexton, D., Lowe, J. (2009). UK Climate Projections: Briefing Report. Fifth report of the UKCP09 scientific reports, 5, Available online: http://ukclimateprojections.defra.gov.uk.

Kaneko, S., Tanaka, K., Toyota, T., Mangi, S. (2004). Water efficiency of agricultural production in China: regional comparison from 1999 to 2002. International Journal of Agricultural Resources, Governance and Ecology, 3, 231-251. doi: http://dx.doi.org/10.1504//JARGE.2004.006038

Karagiannis, G., Tzouvelekas, V., Xepapadeas, A. (2003). Measuring irrigation water efficiency with a stochastic production frontier - An application to Greek out-of-season vegetable cultivation. Environmental \& Resource Economics, 26(1), 57-72. doi: http://dx.doi.org/10.1023/A:1025625402762

Khan, S., Mushtaq, S., Chen, C. (2010). A decision support tool for irrigation infrastructure investments. Irrigation and Drainage, 59(4), 404-418. doi: http://dx.doi.org/10.1002/ird.501

Knox, J., Weatherhead, K., Díaz, J.R., Kay, M. (2009). Developing a strategy to improve irrigation efficiency in a temperate climate: A case study in England. Outlook on Agriculture, 38(4), 303-309. doi:

http://dx.doi.org/10.5367/000000009790422160

Knox, J.W., Kay, M.G., Weatherhead, E.K. (2012). Water regulation, crop production, and agricultural water management-Understanding farmer perspectives on irrigation efficiency. Agricultural Water Management, 108(0), 3-8. doi: http://dx.doi.org/10.1016/j.agwat.2011.06.007

Lansink, A.O., Pietola, K., Bäckman, S. (2002). Effciency and productivity of conventional and organic farms in Finland 1994-1997. European Review of Agricultural Economics, 29(1), 51-65. doi:

http://dx.doi.org/10.1093/erae/29.1.51

Lilienfeld, A., Asmild, M. (2007). Estimation of excess water use in irrigated agriculture: A Data

Envelopment Analysis approach. Agricultural Water Management, 94(1-3), 73-82. doi:

http://dx.doi.org/10.1016/j.agwat.2007.08.005

Mahdi, N., Sghaier, M., Bachta, M.S. (2008). Technical efficiency of water use in the irrigated private schemes in Smar watershed, south-eastern Tunisia. Options Mediterraneenes, Series A, 88, 289-300.

Marques, G.F., Lund, J.R., Howitt, R.E. (2005). Modeling irrigated agricultural production and water use decisions under water supply uncertainty. Water Resources Research, 41(8), W08423. doi: http://dx.doi.org/10.1029/2005wr004048

Matthews, K. (2013). Risk management and managerial efficiency in Chinese banks: A network DEA framework. Omega, 41(2), 207-215. doi: http://dx.doi.org/10.1016/j.omega.2012.06.003

Mays, L.W., 2010. Water Resources Engineering. John Wiley \& Sons.

Oster, J.D., Wichelns, D. (2003). Economic and agronomic strategies to achieve sustainable irrigation. Irrigation Science, 22(3-4), 107-120. doi: http://dx.doi.org/10.1007/s00271-003-0076-4

Pimentel, D., Berger, B., Filiberto, D., Newton, M., Wolfe, B., Karabinakis, E., Clark, S., Poon, E., Abbett, E., Nandagopal, S. (2004). Water resources: Agricultural and environmental issues. BioScience, 54(10), 909918. doi: http://dx.doi.org/10.1641/0006-3568(2004)054[0909:Wraaei]2.0.Co;2

Sexton, T.R., Silkman, R.H., Hogan, A.J. (1986). Data envelopment analysis: Critique and extensions. New Directions for Program Evaluation, 1986(32), 73-105. doi: http://dx.doi.org/10.1002/ev.1441

Shephard, R.W., 1970. Theory of Cost and Production Functions. Princenton University Press.

Simar, L., Wilson, P.W. (1998). Sensitivity analysis of efficiency scores: How to bootstrap in nonparametric frontier models. Management Science, 44(1), 49-61. doi: http://dx.doi.org/10.1287/Mnsc.44.1.49 Simar, L., Wilson, P.W. (2007). Estimation and inference in two-stage, semi-parametric models of production processes. Journal of Econometrics, 136(1), 31-64. doi:

714 http://dx.doi.org/10.1016/j.jeconom.2005.07.009 
Singh, R., Kundu, D.K., Bandyopadhyay, K.K. (2010). Enhancing Agricultural Productivity through Enhanced

Water Use Efficiency. Journal of Agricultural Physics, 10, 1-15.

Speelman, S., D'Haese, M., Buysse, J., D'Haese, L. (2008). A measure for the efficiency of water use and its determinants, a case study of small-scale irrigation schemes in North-West Province, South Africa.

719 Agricultural Systems, 98(1), 31-39. doi: http://dx.doi.org/10.1016/j.agsy.2008.03.006

720 Van Passel, S., Nevens, F., Mathijs, E., Van Huylenbroeck, G. (2007). Measuring farm sustainability and

Varian H., 2010. Intermediate Microeconomics: A Modern Approach, Eighth Edition ed. W. W. Norton \& Company.

Veettil, C.P., Ashok, A., Speelman, S., Buysse, J., Van Huylenbroeck, G. (2011). Sub-vector Efficiency analysis in Chance Constrained Stochastic DEA: An application to irrigation water use in the Krishna river basin, India. Paper provided by European Association of Agricultural Economists in its series 122nd Seminar, February 17-18, 2011, Ancona, Italy with number 98978(98978).

Vico, G., Porporato, A. (2011). From rainfed agriculture to stress-avoidance irrigation: II. Sustainability, crop yield, and profitability. Advances in Water Resources, 34(2), 272-281. doi:

http://dx.doi.org/10.1016/j.advwatres.2010.11.011

Wadud, A., White, B. (2000). Farm household efficiency in Bangladesh: a comparison of stochastic frontier and DEA methods. Applied Economics, 32(13), 1665-1673. doi:

http://dx.doi.org/10.1080/000368400421011

Wambui, N.G., 2011. An assesment on water efficiency in lake Naivasha Basin, in Kenya. Deapartment of Agricultural Economics University of Nairombi.

Wang, X.Y. (2010). Irrigation Water Use Efficiency of Farmers and Its Determinants: Evidence from a Survey in Northwestern China. Agricultural Sciences in China, 9(9), 1326-1337. doi:

http://dx.doi.org/10.1016/S1671-2927(09)60223-6

Weatherhead, E., Knox, J.W., Morris, J., Hess, T.M., Bradley, R.I., Sanders, C.L. (1997). Irrigation demand and on-farm water conservation in England and Wales.

Wilson, P.W. (1993). Detecting Outliers in Deterministic Nonparametric Frontier Models with Multiple Outputs. Journal of Business \& Economic Statistics, 11(3), 319-323. doi: http://dx.doi.org/10.2307/1391956

Wilson, P.W., 2010. Detecing outliers in deterministic nonparametric frontier models with multiple outputs: Correction, unpublished working paper. Department of Economics, Clemson University, Clemson, South Carolina 29634, available on-line at http:/www.clemson.edu/economics/faculty/wilson/Papers/apcorrected.pdf. 
750 Table 1: Descriptive statistics of the inputs and the outputs used in the DEA linear programming 751 model

\begin{tabular}{|c|c|c|}
\hline \multirow[b]{2}{*}{ Inputs and outputs for the DEA model } & \multicolumn{2}{|c|}{ Irrigating Horticulture Farms } \\
\hline & Mean & St. Deviation \\
\hline Area farmed (ha) & 7.172 & 12.17 \\
\hline Total agricultural costs $(£ /$ ha $)$ & 18,564 & 36,440 \\
\hline Water use $\left(m^{3} / h a\right)$ & 2,709 & 3,713 \\
\hline Energy cost $(\xi / \mathrm{ha})$ & 1,715 & 2,400 \\
\hline Total labour (hours/ha) & 2,340 & 3,505 \\
\hline Other agricultural costs ( $E /$ ha $)$ & 10,117 & 18,629 \\
\hline Gross Margin ( $($ /ha) & 41,583 & 60,607 \\
\hline
\end{tabular}


753 Table 2: Descriptive statistics of the variables used for the econometric estimation of the impact of 754 management practices on water use efficiency

\begin{tabular}{lcc}
\hline \multirow{2}{*}{$\begin{array}{l}\text { Variables used in the second stage truncation regression } \\
\text { model }\end{array}$} & \begin{tabular}{c} 
Irrigating Horticulture Farms \\
\cline { 2 - 2 } Bias-corrected water use efficiency
\end{tabular} & $\begin{array}{c}\text { Mean } \\
\text { of cases }\end{array}$ \\
Rainwater collection systems & 0.40 \\
In-field soil moisture measurement & 13 \\
Water balance calculations & 24 \\
Decision support tool & 13 \\
Recycling & 11 \\
Optimised irrigation systems & 6 \\
Trickle/drip/spray lines irrigation system & 30 \\
Other irrigation systems & 33 \\
Drip irrigation systems & 14 \\
Overhead irrigation systems & 2 \\
Combine Drip and Overhead irrigation systems & 12 \\
Combine Trickle Spray and Overhead irrigation systems & 2 \\
Combine Drip and Trickle Spray irrigation systems & 5 \\
Combine Drip, Trickle Spray and Overhead irrigation & 4 \\
systems & 2 \\
\hline
\end{tabular}


756 Table 3: Frequency distribution of technical and water use efficiency under the assumptions of CRS 757 and VRS, and mean of SE.

Irrigating horticulture farms

\begin{tabular}{|c|c|c|c|c|}
\hline \multirow{2}{*}{ Efficiency level (\%) } & \multicolumn{2}{|c|}{ Technical efficiency } & \multicolumn{2}{|c|}{ Water Use Efficiency } \\
\hline & CRS & VRS & CRS & VRS \\
\hline & Number of farms & Number of farms & Number of farms & Number of farms \\
\hline $0<$ Eff $<30$ & 6 & 1 & 29 & 20 \\
\hline $30<$ Eff $<50$ & 8 & 4 & 6 & 7 \\
\hline $50<$ Eff $<70$ & 12 & 15 & 3 & 1 \\
\hline $70<$ Eff $<100$ & 14 & 11 & 2 & 3 \\
\hline$E f f=100$ & 26 & 35 & 26 & 35 \\
\hline Mean Efficiency & 0.74 & 0.85 & 0.51 & 0.65 \\
\hline Mean Scale Efficiency & \multicolumn{2}{|c|}{0.86} & \multicolumn{2}{|c|}{0.67} \\
\hline
\end{tabular}

758

759

pg. 33 
760 Table 4: Estimated technical efficiency, sub-vector efficiency and water excess for the farms in the 761 sample

\begin{tabular}{|c|c|c|c|c|}
\hline FarmID & $\begin{array}{c}\text { Water Use } \\
\left(\mathrm{m}^{3} / \mathrm{ha}\right.\end{array}$ & $\begin{array}{c}\text { Technical } \\
\text { Efficiency VRS }\end{array}$ & $\begin{array}{c}\text { Water Use } \\
\text { Efficiency VRS }\end{array}$ & $\begin{array}{c}\text { Water Savings } \\
\left(\mathrm{m}^{3} / \mathrm{ha}\right)\end{array}$ \\
\hline 1 & 172.61 & 0.45 & 0.15 & 52.15 \\
\hline 5 & 472.24 & 0.70 & 0.17 & 250.05 \\
\hline 6 & 5321.00 & 0.72 & 0.35 & 1973.03 \\
\hline 7 & 1120.93 & 0.93 & 0.75 & 203.34 \\
\hline 9 & 439.00 & 0.69 & 0.25 & 193.16 \\
\hline 10 & 4012.41 & 0.79 & 0.25 & 2183.95 \\
\hline 13 & 4351.47 & 0.64 & 0.08 & 2445.53 \\
\hline 14 & 4735.00 & 0.58 & 0.32 & 1237.26 \\
\hline 15 & 3492.86 & 0.94 & 0.65 & 1015.02 \\
\hline 18 & 5250.00 & 0.79 & 0.31 & 2548.88 \\
\hline 20 & 1929.17 & 0.81 & 0.21 & 1155.38 \\
\hline 26 & 3148.15 & 0.74 & 0.35 & 1212.98 \\
\hline 32 & 379.21 & 0.45 & 0.02 & 164.73 \\
\hline 34 & 1520.60 & 0.69 & 0.07 & 942.01 \\
\hline 36 & 2744.87 & 0.77 & 0.44 & 896.75 \\
\hline 37 & 5509.08 & 0.70 & 0.12 & 3155.60 \\
\hline 42 & 3333.33 & 0.69 & 0.22 & 1569.33 \\
\hline 43 & 329.86 & 0.56 & 0.04 & 170.77 \\
\hline 44 & 2992.86 & 0.89 & 0.82 & 196.33 \\
\hline 50 & 899.00 & 0.70 & 0.11 & 526.18 \\
\hline 52 & 3308.57 & 0.59 & 0.37 & 706.38 \\
\hline 53 & 5384.62 & 0.53 & 0.13 & 2138.23 \\
\hline 54 & 2585.54 & 0.67 & 0.01 & 1689.65 \\
\hline 57 & 3971.63 & 0.56 & 0.13 & 1709.79 \\
\hline 60 & 325.00 & 0.20 & 0.05 & 51.06 \\
\hline 63 & 4227.27 & 0.97 & 0.94 & 135.27 \\
\hline
\end{tabular}

762

pg. 34 
764 Table 5: Returns to scale in relation to farm size

\begin{tabular}{cccccc}
\hline \multirow{2}{*}{ Group } & \multirow{2}{*}{ Returns to Scale } & \multicolumn{3}{c}{ Farm Size } & \multirow{2}{*}{$\%$} \\
\cline { 3 - 5 } & & Large & Medium & Small & \\
\hline $\begin{array}{c}\text { Horticulture } \\
\text { Farms }\end{array}$ & CRS & 8 & 11 & 7 & 40 \\
& DRS & 8 & 1 & 0 & 14 \\
& IRS & 6 & 12 & 13 & 47 \\
\hline
\end{tabular}

765

766

767

768

769

pg. 35 
Table 6: Truncated regression. The dependent variable is the vector of the reciprocal of DEA estimate 771 (distance function), estimated in the input-oriented sub-vector DEA model with variable returns of 772 scale assumption.

\begin{tabular}{llrr} 
& Observed Coef. & Std. Err. & t-value \\
\hline (Intercept) & $0.38 * * *$ & 0.06 & 6.44 \\
Rainwater collection systems & 0.11 & 0.09 & 1.12 \\
In-field soil moisture measurement & 0.03 & 0.07 & 0.50 \\
Water balance calculations & -0.09 & 0.10 & -0.89 \\
Decision support tool & $0.24 *$ & 0.11 & 2.21 \\
Recycling & $0.26 *$ & 0.13 & 2.01 \\
Optimised irrigation system & 0.03 & 0.09 & 0.34 \\
Other irrigation systems & $-0.25 * *$ & 0.10 & -2.58 \\
Drip irrigation systems & $-0.43 *$ & 0.18 & -2.37 \\
Overhead irrigation systems & $-0.22 * *$ & 0.08 & -2.59 \\
Combine Drip and Overhead irrigation systems & -0.11 & 0.18 & -0.62 \\
Combine Trickle Spray and Overhead irrigation & $-0.41 *$ & 0.19 & -2.21 \\
systems & & 0.13 & 0.72 \\
Combine Drip and Trickle Spray irrigation systems & 0.09 & 0.18 & -1.05 \\
Combine Drip, Trickle Spray and Overhead & -0.19 & 0.10 & -14.74 \\
\hline Sigma & $-1.47 * * *$ & & \\
\hline
\end{tabular}

773 Signif. codes: '***' $0.001,{ }^{\prime * * \prime} 0.01,{ }^{\prime * \prime} 0.05,{ }^{\prime \prime \prime} 0.1,{ }^{\prime}$ ' 1 - No of Bootstraps 2000

774 Log likelihood $=-6.21$

775 Wald $\chi^{2}(15)=40.17$, Prob $>\chi^{2}=0.00$ 


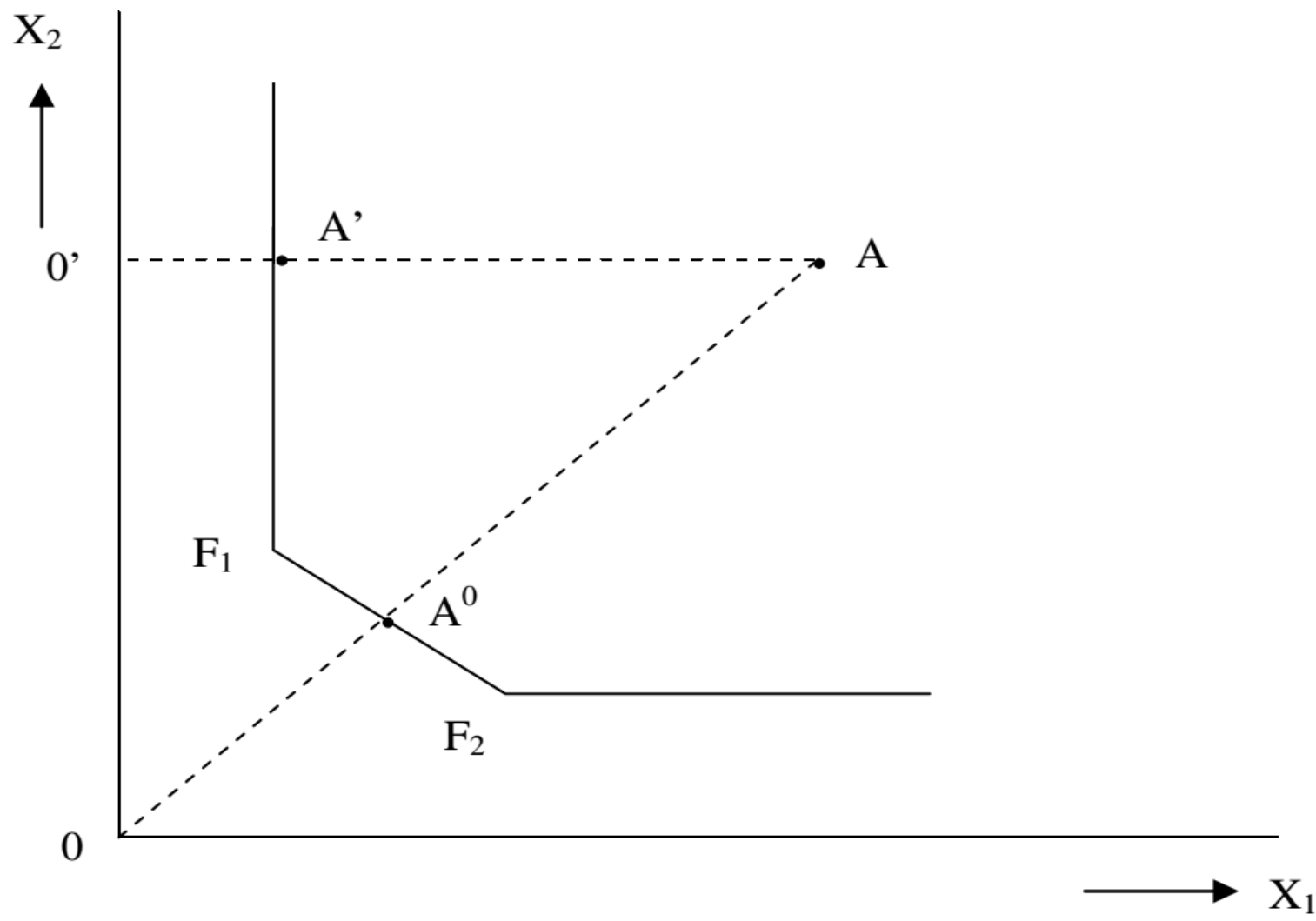
780 Figure 1: Graphical representation of the measurement of technical efficiency and sub-vector
781 efficiency using DEA for an example with two inputs and one output (adapted from Lansink et al. 782 (2002))

783 